
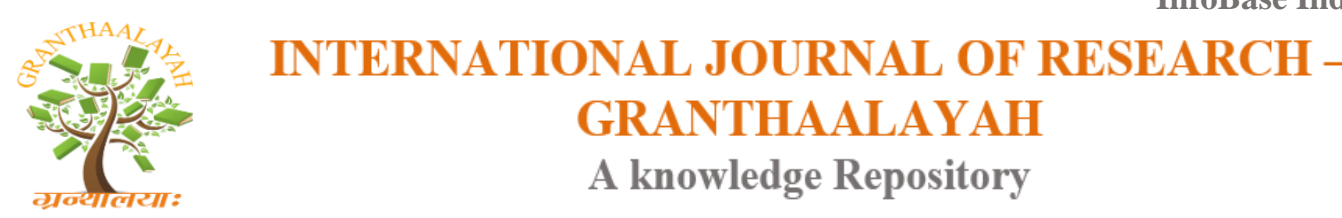

Science

\title{
STUDY ON THE STATUS OF BOVINE TICK INFESTATION, IN GUBA- KORICHA DISTRICT IN WEST HARARGHE ZONE, EAST - ETHIOPIA
}

\author{
Henok Ababa*1, ${ }^{* 1}$ segaye Negese ${ }^{2}$, Bekele Birru ${ }^{3}$, Kifle Nigusu $^{4}$, Shibire Araya $^{5}$, \\ Wendwosen Gebireamlak ${ }^{6}$, Shimelis Asres ${ }^{7}$ \\ *1, 2, 3, 4, 5, 6,7 Hirna Regional, Veterinary Laboratory, Oroima Regional State, P.O. BOX 34, \\ Ethiopia
}

DOI: https://doi.org/10.29121/granthaalayah.v5.i4.2017.1813

\begin{abstract}
A cross-sectional study was conducted from November 2010 to April 2011 to determining the prevalence of tick infestation, to identify the common tick species in cattle and to assess the major risk factors associated with the occurrence of tick species in Guba koricha district West Hararghe zone of Oromia regional state, southeast Ethiopia. Ticks were collected by searching and half body of animals using forceps on different regions of the animals' body. A total sample of 384 cattle, 234 were found to be infested by one or more tick species an overall prevalence of $60.9 \%$. The most predominant isolated ticks species in this study were R. pullchelus with isolation rate of $49.4 \%$ followed A. Varigatum with isolation rate of $30.3 \%$, H. marginatum rufipes, the third predominant with isolation rate $11.8 \%$. However, A. gemma, H. trucatum and R. Evertsi-evertsi was the least isolate which accounts for 3.6\%, 2.4\% and $2.35 \%$ respectively. Age, sex and body conditions scoring were found to be important risk factors associated with tick infestation. The prevalence of tick infestation between age and sex was statistically significant $(\mathrm{X} 2=32.3075, \mathrm{CI}=0.1323358-0265075, \mathrm{P}=0.000 \quad$ and $\mathrm{X} 2=5.117, \mathrm{CI}=0.1953184$ $0.0061713, \mathrm{P}=0.037)$ respectively. However, breed and body condition were not statistically significant $(\mathrm{P}>0.05)$. Hereof, Ticks are obligate, blood feeding ecto-parasites that cause severe damage to the hides and skins of domestic cattle due to this reduce the foreign exchange of the country; and transmit tick borne diseases. Therefore, effective tick control programs should be formulated and implemented at national or regional level.
\end{abstract}

Keywords: Control Program; Guba Koricha; Prevalence And Tick.

Cite This Article: Henok Ababa, Tsegaye Negese, Bekele Birru, Kifle Nigusu, Shibire Araya, Wendwosen Gebireamlak, and Shimelis Asres. (2017). "STUDY ON THE STATUS OF BOVINE TICK INFESTATION, IN GUBA-KORICHA DISTRICT IN WEST HARARGHE ZONE, EAST - ETHIOPIA." International Journal of Research - Granthaalayah, 5(4), 202-213. https://doi.org/10.29121/granthaalayah.v5.i4.2017.1813. 


\section{Introduction}

Ethiopia, located in the horn of Africa, it has an extremely diverse topography; a wide range of climatic features and multitudes of agro-ecological zonation which makes the country suitable for different agricultural production for 85-90 \% of the people of Ethiopia is agriculture Error! Reference source not found. Ethiopia is endowed with the largest livestock population in Africa. Therefore, livestock play a vital role in the farming system of the country mainly used for draught power, milk and meat production and source of manure. Unfortunately, the contribution of this huge natural resource to human nutrition and export earnings is dis-proportionally low. The Ethiopian livestock contributes only $15 \%$ to the GDP. Total herd meat off-take is estimated at around $7 \%$ annually, which is perhaps one-third lower than the average for tropical Africa. Cattle are a prime resource for the people and government of Ethiopia. The country has the largest cattle population in Africa, estimated at 35 million head Error! Reference source not found.

Ticks are obligate, blood feeding ecto-parasites of vertebrates, particularly mammals and birds. It has been estimated that about $80 \%$ of the world population of cattle are infested with ticks.

The lifecycle of ticks (both Ixodids and Argasids) undergo four stages in their development; eggs, 6-legged larva, 8-legged nymph and adult Error! Reference source not found..Based on the number of hosts required to complete their development during their life cycle they can be classified as one-host, two-host and three-host ticks Error! Reference source not found..Although, only relatively few of more than 889 species of tick in the world are important to man and his domestic animals, these few species must be controlled if livestock production is to meet world needs for animal protein Error! Reference source not found.. Over 79 different species are found in eastern Africa but many of these appear to be of little or no economic importance Error! Reference source not found..But out of over 79 ticks species in Ethiopia, there are 47 species of ticks found on livestock and most of them have importance as vector and disease causing agents and also have damaging effect on skin and hide production Error! Reference source not found...and also they down grade hide and skins quality and reduce milk and wool production, reduce productivity and increase susceptibility to the other diseases [Error! Reference source not found.].Ticks also have adverse effect on livestock in several ways and parasitize a wide range of vertebrate hosts and transmit a wide variety of pathogenic agents than any other group of arthropods Error! Reference source not found.. They transmit protozoa, bacterial, rickettsia and viral diseases in domestic animals. They also cause nonspecific symptom like anemia, dermatosis, toxicities and paralysis Error! Reference source not found.In Ethiopia ticks are common in all agro ecological zones of the country Error! Reference source not found. Therefore, relevant data on the distribution of ticks is essential for the development of effective tick and tick borne disease control strategies. Studying ticks on livestock under their natural conditions without any control measure is also useful for understanding the host parasite relationship and variation of tick population in different agroecological zone.

Different tick species are widely distributed in Ethiopia and a number of researchers reported the distribution and abundance of tick species in different parts of the country.Amblyomma tick is one of the most abundant tick genera and has been reported in many parts of the country, such as 
Nekemte Error! Reference source not found., Hararghe Error! Reference source not found. Asella Error! Reference source not found., Awass aError! Reference source not found., Mizan Teferi Error! Reference source not found. and Jimma Error! Reference source not found. with highest prevalence rate as well as Rhipicephalus is also predominant genera and has been reported with highest prevalence in GamoGofa Error! Reference source not found., Bale Error! Reference source not found. and Southern Sidamo Error! Reference source not found. Boophilus and Hyalomma ticks also have a significant role. The populations of tick are influenced by climatic changes, which affect the rate of tick population on the ground, host resistance and natural enemies Error! Reference source not found.. Amblyomma coherence is prevalent and abundant in western humid highland areas of Ethiopia. Boophilus decoloratus and Rhipicephalus evertsi evertsi are widely distributed in most altitudinal ranges Error! Reference source not found.. Therefore, this study was designed with the aims of

- To determining the prevalence of tick infestation of cattle in the study district.

- To identify the common tick species in Gubakoricha district.

- To assess the major risk factors associated with the occurrence of ticks species in the study area.

\section{Materials and Method}

\subsection{Study Area}

The study was conducted in Guba Koricha is one of the District located in the West Hararghe Zone in the Oromia Region of Ethiopia, according to the OCHA map (2005) is bordered on the south by Darolebu, on the southwest by the Arsi Zone, on the west by the Afar Region, on the north by Mieso, on the northeast by Chiro, on the east by Habro, and on the southeast by Boke. Although coffee is an important cash crop of this District, less than 20 square kilometers are planted with this crop. The altitude of the study area ranges from 1300 to 2800 meters above sea level while the minimum annually temperature ranges between $22^{\circ} \mathrm{C}$ and $28^{\circ} \mathrm{C}$. The mean annually rain fall of the area ranges from about 1050 to $2160 \mathrm{~mm}$.

\subsection{Study Population}

According to Error! Reference source not found.Error! Reference source not found.Error! Reference source not found.the live stocks population of Guba koricha generally, about 219,593 live stocks, out of this 83,168 are cattle and the rest are other species of animals. The study populations were constituted in all breeds but the mostly populated breed in the area was indigenous or local breeds kept under mixed farming system and People of the district are directly depending on livestock and agricultural production to boost the quality and quantity of this product.

\subsection{Study Design}

A cross-sectional study was conducted from November 2010 to April 2011 to determining the prevalence of tick infestation, to identify the common tick species in cattle and to assess the major risk factors associated with the occurrence of tick's species in Guba koricha district West Hararghe zone of Oromia regional state. 


\subsection{Sampling and Sample Size Determination}

For estimation of the prevalence of ticks, since there was no work done in the study area, the cattle to be examined were selected by simple random sampling method, and the sample size was determined by assuming of using the formula described by Error! Reference source not found..The expected prevalence of Ixodidae ticks of cattle in Guba koricha District was assumed as $50 \%$. The parameters used were $95 \%$ confidence interval and $5 \%$ desired level of precision. By substituting these values in the formula, the sample size taken was $n=384$

$\mathrm{N}=1.96^{2} \mathrm{Pexp}(1-\mathrm{Pexp})$

$\mathrm{D}^{2}$

\subsection{Study Methodology}

\subsubsection{Sampling Procedure and Techniques}

Ticks were successfully collected from cattle after being restrained using strong crushes, by physical handling. Ticks were collected by searching and half body of animals using forceps on different regions of the animals' body. Ticks were collected from ears, heads, dewlaps, belly/flunk, udder/scrotum, perineum and legs/tails in the separated sample bottles. The skin of each study cattle was inspected for the presence of ticks. All adults (Both sexes) were collected by using universal bottles; collected ticks were preserved in $70 \%$ ethyl alcohol and transported to Hirna regional veterinary laboratory for the ticks were counted and subsequently identified to genus and species level by using stereomicroscope, according to standard identification keys given by Error! Reference source not found.. First ticks were seen grossly, classified to different genera levels, and identified into their species level depending up on their morphological structures.

During tick identification in the laboratory the sample were put on Petridis and examined under stereomicroscope.

\subsection{Methods of Data Management and Statistical Analysis}

The data collected during sampling and laboratory findings were entered and stored in MS-excel. Before subjected to statistical analysis, the data were thoroughly screened for errors and properly coded. An intercooled Stata 9 software package was used to perform the statistical analysis. Descriptive statistical analysis such as table was used to summarize and present the data collected. Ticks prevalence was calculated as percentage by dividing the number of animals positive to the total sampled animals. Pearson chi-square $\left(\chi^{2}\right)$ test was employed to assess the existence of association between tick infested cattle's and different potential risk factors considered in the study. For this analysis P-value $<0.05$ were considered significant whereas $\mathrm{P}$ value $>0.05$ considered non-significant.

\section{Results}

\subsection{Prevalence of Ticks on Cattle in Guba Koricha District}


Out of the total sample of 384 cattle, 234 were found to be infested by one or more tick species an overall prevalence of $60.9 \%$. A total 1572 Ixodid ticks were collected among which three genera of ticks were identified. Rhipicephalus was the most abundant $(51.8 \%)$ genus and Hyalomma was confirmed to be the least prevalent (14.25\%) tick genus (Table 1).

Table 1: Distribution of tick genera in Guba koricha district

\begin{tabular}{ll}
\hline Genus & Percentage of total tick genera \\
\hline Rhipicephalus & $51.8 \%(814 / 1572)$ \\
Amblyomma & $33.96 \%(534 / 1572)$ \\
Hyalomma & $14.25 \%(224 / 1572)$ \\
\hline
\end{tabular}

The results of tick identification from infested cattle's revealed that involvements of 1572 Ixodid ticks were collected among which three genera and six species of ticks were identified. Therefore, the most predominant isolated ticks species in this study were R.pullchelus with isolation rate of $49.4 \%$ followed $A$. Varigatum with isolation rate of $30.3 \%, H$. marginatumrufipes, the third predominant with isolation rate $11.8 \%$.However, A. gemma, $H$. trucatum and $R$. Evertsi-evertsi was the least isolate which accounts for $3.6 \%, 2.4 \%$ and $2.35 \%$ respectively. The tick identification rate and their prevalence are shown on (Table 2)

Table 2: Results isolation of tick's species in cattle's

\begin{tabular}{ll}
\hline Tick species & Total count and prevalence (\%) \\
\hline R.Pullchelus & $(49.4 \%) 777$ \\
A. Varigatum & $(30.3 \%) 477$ \\
A. gemma & $(3.6 \%) 57$ \\
R. Evertsi & $(2.35 \%) 37$ \\
H. trucatum & $(2.4 \%) 38$ \\
H. marginatumrufipes & $(11.8 \%) 186$ \\
\hline
\end{tabular}

During the study period, each species of ticks were collected from various favorable bodies of cattle's and also we are collecting multi species ticks on some attachment site. The observed proportion of attachment sites for each species of the ticks during this study was summarized in table 3 .

Table 3: Favorable attachment sites of tick's species

\begin{tabular}{ll}
\hline Species of ticks & Site of attachment \\
\hline Ambylomma species & Brisket, udder, scrotum and dewlap \\
Rhipicepahlus species & Tail, head, ear and angonetial \\
\hline
\end{tabular}


Hyalomma species Scrotum, udder and brisket

During the study time, we are revealing that sex ratio of adult ticks in the study area, the number of Male tick's species higher than female tick's species in $R$. Pullchelus, A. Varigatum, $R$. Evertsi-evertsi, $H$. trucatumand $H$. marginatumrufipes but in the case of $A$. gemma tick species the number of female ticks species higher than male ticks species(Table 4).

Table 4: Distribution and sex ratio of adult tick species

\begin{tabular}{llllll}
\hline Tick species & Male & Female & M:F ratio & Total & Prevalence \\
\hline R. Pullchelus & 580 & 197 & $2.94: 1$ & 777 & $49.4 \%$ \\
A. Varigatum & 365 & 112 & $3.26: 1$ & 477 & $30.3 \%$ \\
A. gemma & 9 & 48 & $1: 5.3$ & 57 & $3.6 \%$ \\
R. Evertis & 37 & - & 0 & 37 & $2.35 \%$ \\
H. trucatum & 38 & - & 0 & 38 & $2.4 \%$ \\
H. marginatumrufipes & 148 & 38 & $3.9: 1$ & 186 & $11.8 \%$ \\
\hline
\end{tabular}

From three genera and six species identified in the study area and their relative infestation rate of R.Pullchelus (33.8\%), A. Varigatum (21.8\%) and H. marginatum rufipes (15.38\%) were more prevalent on the animals of current study. However, A. gemma (8.97\%), Multi species (8.12\%), $R$. Evertsi-evertsi(7.26\%) and H. trucatum (4.7\%) were the least tick species found on the body of the animals respectively (Table 5).

Table 5: Distribution of tick species on the animal

\begin{tabular}{lll}
\hline Ticks species & \multicolumn{2}{c}{ Total animals examined N= 234 } \\
\cline { 2 - 3 } & Positive animals & Prevalence \\
\cline { 2 - 3 } R. Pullchelus & 79 & $33.8 \%$ \\
A. Varigatum & 51 & $21.8 \%$ \\
A. gemma & 21 & $8.97 \%$ \\
R. Evertis & 17 & $7.26 \%$ \\
H. trucatum & 11 & $4.7 \%$ \\
H. marginatumrufipes & 36 & $15.38 \%$ \\
Multi species & 19 & $8.12 \%$ \\
\hline
\end{tabular}

In this study, different possible risk factors like age, sex, breed and body condition scoring were also assessed and the result was as indicated here in table 6.

Age: one of a possible risk factor for the occurrence ticks infestation, hereof among the three age categories the highest ticks infestation prevalence was recorded in old age $(75.14 \%)$ followed by adult age $(66 \%)$ and lower on young age $(35.85 \%)$ (Table 6).However, there is 
statistical $(\mathrm{p}<0.005)$ significant between infestation of tick and age groups $\left(\mathrm{X}^{2}=32.3075\right.$, $\mathrm{CI}=0.1323358-0265075, \mathrm{P}=0.000)$.

Sex: comparison was made on the prevalence of female and male. Out of animals sampled, the majority or $54.4 \%$ were females while about $45.6 \%$ of them were males. The tick prevalence was $63.6 \%$ and $57.3 \%$ in female and male respectively (Table 6). However, there is statistical $(\mathrm{p}<0.05)$ significance between the two sexes $\left(\mathrm{X}^{2}=5.117, \mathrm{CI}=0.1953184-0.0061713, \mathrm{P}=0.037\right)$.

Breed: As indicated in the (Table 6) below, the study revealed that the prevalence of tick infestation in Local breeds was that $63.03 \%$ recorded and the prevalence of tick infestation in Cross breed were found to be $33.03 \%$. There is no significant difference $(\mathrm{P}>0.05)$ in the prevalence of tick infestation among the two breeds of animals during out survey $\left(\mathrm{X}^{2}=0.4005\right.$, $\mathrm{CI}=0.1301061-0.2381844, \mathrm{P}=0.564)$.

Body condition score: were also considered during examination, animals were divided into three body condition scores as shown in the (table 6). These are, good, medium and poor. Out of 384 animals examined 75 animals were poor body condition state and out of these $65(86.7 \%)$ animals were positive for tick infestation, therefore, high prevalence of ticks infestation was recorded in poor body condition followed by 198 animals were in medium body condition and out of these 124 (62.6\%) animals were positive for tick infestation, and the rest 111 animals were in good body condition, out of these 45 (40.5\%) animals were positive for tick infestation. These result shows that body condition scoring have no significant ( $p>0.005$ ) relation with tick infestation $\left(\mathrm{X}^{2}=0.8116, \mathrm{CI}=0.039221-0.0968792, \mathrm{P}=0.405\right)$.

Table 6: Ticks infestation with regard to potential risk factors

\begin{tabular}{llllll}
\hline Variables & Classification & No of sample & No of positive & $\begin{array}{l}\text { Infestation } \\
\text { Prevalence }\end{array}$ & Significance \\
\hline \multirow{3}{*}{ Age } & Young & 53 & 19 & $35.85 \%$ & $\mathrm{X}^{2}=32.3075$ \\
& Adult & 150 & 79 & $66 \%$ & $\mathrm{P}=0.0000$ \\
& Old & 181 & 136 & $75.14 \%$ & \\
Sex & Male & 175 & 101 & & \\
& Female & 209 & 133 & $67.7 \%$ & $\mathrm{X}^{2}=5.3117$ \\
& & & & $63.6 \%$ & $\mathrm{P}=0.037$ \\
Breed & Local & 357 & 225 & $63.03 \%$ & $\mathrm{X}^{2}=0.4005 \mathrm{P}=0.564$ \\
& Cross & 27 & 9 & $33.3 \%$ & \\
& & & & & \\
BCS & Poor & 75 & 65 & $86.7 \%$ & $\mathrm{X}^{2}=0.8116$ \\
& Medium & 198 & 124 & $62.6 \%$ & $\mathrm{P}=0.405$ \\
& Good & 111 & 45 & $40.5 \%$ & \\
\hline
\end{tabular}

\section{Discussion}

The distribution and abundance of tick species infesting domestic ruminants in Ethiopia vary greatly from one area to another area. The study was carried out to determine the prevalence of tick infestation in cattle, to assess the major risk factors in the study areas. From the total of 384 local and cross breed cattle, the overall prevalence recorded was $60.9 \%$. It is disagree from the 
findings of Nigatu and Teshome, who reported an overall prevalence of (89.4\%). However, it is higher than the findings of Belew and Mekonnen who reported an overall prevalence of $33.21 \%$. This difference could be due to the difference in the agro climatic condition of the study areas. Tick activity was influenced by rainfall, altitude and atmospheric relative humidity Error! Reference source not found..From infested cattle's three genera of hard ticks were identified, namely Rhipicephalus (51.8\%), Amblyomma (33.96\%) and Hyalomma (14.25\%) and1572 Ixodid ticks were collected from six species of ticks. Therefore, the predominant isolated tick's species were $R$. pullchelus with isolation rate of $49.4 \%$, followed A. Varigatum with isolation rate of $30.3 \%$, H. marginatum rufipes, the third predominant with isolation rate $11.8 \%$. However, $A$. gemma, $H$. trucatum and $R$. Evertsi-evertsi was the least isolate which accounts for $3.6 \%, 2.4 \%$ and $2.35 \%$ respectively, were identified in the study area.R. Pullchelus, was the most abundant of all tick species comprising (49.4\%), of the collected ticks in the study areas. This finding was disagree, with the results have been reported by Error! Reference source not found..It was collected from different part of Ethiopia in eastern Tigray, southern SNNP, Afar, Harar, Somalia and Dire Diwa.followed by $R$. Pullchelus the most abundant tick's species in the study area was A. Varigatum $30.3 \%$. This results was agree with the results have been reported by Error! Reference source not found. in North Omo, and in awasa Error! Reference source not found.. In addition, this could be because $A$. variegatum is the most common and widely distributed cattle tick in Ethiopia Error! Reference source not found..

It has a great economic importance, because it is an efficient vector of Cowderia ruminatum and greatest damage to skin and hide, due to its long mouth parts, so it will reduce the value on world market Error! Reference source not found. Also, ulcer caused by this tick species becomes favorable site for secondary bacterial infection like Dermatophilus congolensis.

H. marginatum rufipes was identified as the $3^{\text {rd }}$ abundant ticks species collected in the study area. This tick's species was collected restricted area of the warm, moderately dry midland with an altitude of 1800 to 1950 (Error! Reference source not found.). Error! Reference source not found.indicate that widely distribute in the most arid topical parts of Africa and in Ethiopia most often collected between 1000 and 2000 m.a.s.l and rare in western highland of areas. Therefore, the finding of Error! Reference source not found.was agreed with the present study. The study Error! Reference source not found. in Wolayita awraja and Error! Reference source not found. in north wollo zone kobo girana valley and Error! Reference source not found. at Abernosa ranch are in agreement with the present finding.

A. gemma was the $4^{\text {th }}$ abundant tick species collected and represent $(3.6 \%)$ of the total collection. This tick species was collected from restricted area of arid, semi-arid and rift valley restricted to semi-arid plain and bush land receiving 100 to $800 \mathrm{~mm}$ rainfall annually Error! Reference source not found., Error! Reference source not found. stated that A. gemma widely distributed in woodland, bush land, wooded and grassland in arid and semiarid area between altitude 500 to $1750 \mathrm{~m}$ above sea level and receiving 350 to $750 \mathrm{~mm}$ annual rain fall.

$H$. trucatum is the least abundant tick species constituting $2.4 \%$ of the total of adult tick collection in the study area. This results was disagree with the results have been reported by Error! Reference source not found. in Borena this due to the agro ecological condition which is low land and receive small rainfall but in our study areas altitude factors which govern the distribution of ticks in the study area. In sub shara Africa, H. trucatum is very widespread and 
often common. It is abundance may be influenced by the abundance of hare that are preferred hosts of the mature stages Error! Reference source not found..

R. evertis is the least abundant tick species constituting $2.35 \%$ of the total of adult tick collection in the study area. In contrast to this study this tick species was reported to be prevalent by other authors such as Error! Reference source not found.,Error! Reference source not found. mentioned that the native distribution of $R$. eversi in Ethiopia seems to be connected with middle highland, dry savannas and steppes in association with zebra and ruminant.

The geographical distribution of survey of tick has conducted in Gonder awraj Error! Reference source not found. found that $R$. evertsi was the most abounded tick species of the area. This may due to the geographic location, seasonal variation of the area or may be due to variation in microclimate factors Error! Reference source not found. including higher rainfall associated with high soil moister content that is favorable on the survival of tick vectors. This tick shows no apparent preference for any particular altitude rainfall or season Error! Reference source not found..

The present study also revealed that ticks select favorable site for their attachments on the body of cattle Error! Reference source not found. in South Africa who reported that similar favorable site of ticks to attach themselves on the cattle's body. Information on predilection sites of ticks is helpful in spraying individual animals since it gives a clue as to which part of the body requires more attention Error! Reference source not found.

The male to female rations of all ticks species except in the case of A. gemma ticks species the number of female ticks species higher than male ticks species. The male to female rations of $R$. Pullchelus, A. Varigatum, H. marginatum rufipes, A. gemma, H. trucatum and $R$. Evertis were similar to previous reports Error! Reference source not found.Error! Reference source not found.Error! Reference source not found. Except the females of A. gemma outnumbered than males in this study probably due to small size of male which may, all other species of ticks suggesting that male out number that the female ticks could be the fact that fully engorged female tick drops off to the ground to lay eggs while male tends to remain on the host up to several months to continue feeding and mating with other females on the host before dropping of Error! Reference source not found.

During the study period, the prevalence of tick infestation was assessed between three age group cattle. The adult and old are more sustainable than young because the young are not often driven with adult and old age group into grazing and water points. This practice naturally reduces the chance exposer of young cattle to ticks.

During the study period, the prevalence of tick infestation was assessed between sex of animals higher prevalence was recorded in female animals (63.6\%) compared to male (57.7\%). This variation may be associated with male animals, which were kept properly in the house with good management system for beef purpose whereas, female animals grazing on field all day may be exposed to tick infestation. In current study, there is significant association of tick infestation between sexes of animal. This founding disagrees with Error! Reference source not found.

The study also revealed that the prevalence of tick infestation was assessed between local and cross breeds was recorded $63.03 \%$ and $33.03 \%$ respectively. The fact that more tick burden was 
recorded in local breed as compare to cross breed animals this due to differences in management systems, lack of supplementary feeding to local cattle breeds, or lack of control measures against tick on local cattle breeds. Furthermore, it can be assumed that it might be due to lack of interest of farmers about local cattle and taking more care to cross breed. In current study there is no significant association of tick infestation between two breed of animal $\left(\mathrm{X}^{2}=0.4005\right.$, $\mathrm{CI}=0.1301061-0.2381844, \mathrm{P}=0.564)$

\section{Conclusion and Recommendation}

Ticks are obligate blood feeding ectoparasites of vertebrates, among ecto-parasite it cause the greatest economic loss in livestock population either by transmitting a wide variety of TBDs or by affecting the health of animals as well as the quality of hide and skins. In this study an overall prevalence of tick infestation $60.9 \%$ were obtained by using half body count and stereomicroscope. The main tick genera found in Ethiopia are Amblyomma, Boophilus, Haemaphysalis, Hyalomma and Rhipicephalus. From this genus, the most important and abundant tick species investigated in the study area were R. Pullchelus, A. Varigatum, A. gemma, $R$. Evertis, $H$. trucatum, and $H$. marginatum rufipes. Among the possible risk factors considered in this study; age, sex, breed and body condition scoring. Whereas age and sex have significant association with infestation of tick. Furthermore, predilection sites are identifies that helps in designing control methods and which parts of the cattle's body to be covered while using ectoparasiticide chemicals. Therefore, to minimize the impact effective tick control program should be formulated and implemented at national and regional level based on the distribution pattern of ticks and factors responsible for their distribution. In light of the above conclusion the following recommendations are forwarded:-

- Tick should be managed at an economical acceptable level by a combination of techniques and this requires familiarities with the tick species present and an understanding of their epidemiology for the continuous understanding of improved control strategies.

- Awareness creation for farmers and extension agents to accept the benefits gained from both boosting immunity to TBD and achieving host resistance to ticks that would result from relaxed tick control regimes.

- Adjust animal husbandry practice based on defense reaction of the animal against tick.

- A strong veterinary service structure has to be established to strengthen tick surveillance network at national level, co-ordinate data collection, implement appropriate control and preventive measures.

\section{Acknowledgements}

The authors would like to thank all the staffs of Hirna regional veterinary laboratory for their technical assistance.

\section{References}

[1] Behailu, A. (2004). A study of ticks and tick-borne protozoans in cattle at Assela, Arsi Zone (DVM thesis). FVM, Addis Ababa University, DebreZeit, Ethiopia. 
[2] Belete, M. (1987). A preliminary survey of ticks on four domestic animals in Nekmet Awarja. DVM Thesis, Faculty of Veterinary Medicine, Addis Ababa University, DebreZeite, Ethiopia.

[3] Belew, T. \& A. Mekonnen, (2011). Distribution of Ixodid Ticks on Cattle in and Around Holeta Town Ethiopia. CAVM, JU, Ethiopia. Global Veterinaria, 7(6): Pp.527-531.

[4] Bekele, H. (1987). Study of the topographical distribution of tick on economically important

[5] Domestic animals in Illubabor. DVM thesis, FVM, Addia Ababa University, Debrezeit, Ethiopia.

[6] Central Statistics Authority CSA. (2002): Ethiopian statistical abstract. Addis Ababa, Ethiopia.

[7] Central Statistics Authority CSA. (2004). Ethiopia agricultural sample enumeration result for SNNPR. Statistical report on livestock and farm implements. Part IV: Pp.29-304.

[8] Cumming, G.S., (1999). Host distributions do not limit the species ranges of most African ticks (Acari: Ixodida) Bulletin of Entomological Research (1999), 89: Pp.303-327.

[9] De Castro, J. (1997). Sustainable ticks and tick-borne disease control in livestock improvement in developing countries. Vet. Parasitology. 71: Pp.69-76.

[10] Dejenu, G. (1988). A preliminary survey on tick on. (Acari: Ixidida). Annu. Rev. Ecol. Syst., 20: Pp. 396-430.

[11] Drummond, R.O. (2007). Tick borne livestock diseases and their vector. World Animal

[12] Review 3.htm

[13] Endale, B., (2006). A survey on tick of cattle in Ambo area, western Ethiopia (DVM thesis), Addis Ababa .University, Ethiopia. (Under publish).

[14] Eshetu, M. (1988). Survey of geographic distribution of ticks in Gonderawraja. DVM Thesis, faculty of veterinary medicine, Dberezeit, Ethiopia.

[15] Gubakoricha District Agricultural Beruea, (2009).

[16] Gulilat, A., (1987). A preliminary survey of ticks on domestic animals in Harraghe Administrative region. DVM thesis, faculty of veterinary medicine, Addis Ababa University, Deberezeit, Ethiopia.

[17] Howell, CJ, Walker, JB., \& Nevil, EM (1978). Ticks, Mites and Insects infesting domestic animals in Republic of South Africa department of agricultural technical service. Science bulletin of the department of agricultural technical service in Republic of South Africa. Pp. 1-13.

[18] Jewaro, A. (1986). A survey of tick and tick born disease in Gamogofa administrative region. DVM Thesis, faculty of veterinary medicine, Addis Ababa University, Deberezeit, Ethiopia.

[19] Kassa, B. (2005). Standard veterinary laboratory diagnostic manual. Veterinary diagnostic laboratory, college of veterinary medicine at the University of Illinois at urbana, urbana.ILUSA.

[20] Mehari, B. (2004). Distribution of livestock tick species in Awassa area. DVM Thesis, faculty of veterinary medicine, Addis Ababa University, Deberezeit, Ethiopia.

[21] Mesele, A. (1989). Bovine tick survey in Bahir Dar Awraja. DVM thesis, Faculty of Veterinary Medicine, Addis Ababa University, Debrezeit. Ethiopia.

[22] 20. Minjauw, B., \& McLeod, A. (2003). Tick borne diseases and poverty. The impact of ticks and tick borne diseases on livestock owners in India and Eastern health program center for tropical veterinary medicine, University of Edinburgh, UK. Pp. 24-57.

[23] Mohamed, B., Belay, A \& Hailu, D. (1997). Species composition, prevalence and seasonal variations of ixodid cattle ticks in and around Haromaya town. Academic journal. CAVM, JU, Ethiopia. Pp. 132-137.

[24] Morel, P. (1980). Study on Ethiopian ticks (Acaridae: Ixodidae). 1st.Ed. Republic of France, Ministry of Foreign affairs, French Vet. Mission, Addis Ababa, Ethiopia Pp. 15-183.

[25] Nigatu, K., \& F. Teshome. (2012). Population Dynamics of ectoparasite in Western Amhara National Regional States, Ethiopia, Journal of Vet. Med. And Animal Health, 4(1): Pp.22-26.

[26] Oliver, J. (1989). Biology and systematics of ticks (Acari: Ixidida). Annu. Rev. Ecol. Syst., 20(1): Pp. 397-430. 
[27] Pegram, R., H. Hogstral, H., \& Wassef. (1981). Ticks (Acari: Ixodoidea) of Ethiopia. I. Distribution, ecology and host relationship of species infesting livestock. Bull. Of Intomol. Res., 71: Pp. 339-359.

[28] Regassa, A. (2001) Tick Infestation of Borana Cattle in the Borana Province of Ethiopia. Onderstepoort Journal of Veterinary Research, 68, Pp. 41-45.

[29] Sebsibe, B. (1988); A preliminary survey of tick distribution in Southern Sidamo, DVM Thesis, FVM, AAU, DebreZeit, Ethiopia.

[30] Seid, B. ( 2004). A survey of cattle tick species in and around Mizan- Teferi, Bench Maji zone and SNNPRS. DVM Thesis, AAU, FVM, DebreZeit, Ethiopia.

[31] Singh, AP., Singla, LD., \& Singh, A. (2000). A study on the effect of microclimate factors on the seasonal population of dynamics of Boophilus micopus (Canes, 1888) infesting the cross bred cattle of Ludhiana district. Int. j. Anim. Sci. 15(1): Pp. 29-31.

[32] Siyoum, Z. (2001). Study on tick and tick borne disease on cattle at Girran valley in the North WolloZone, proceeding of Ethiopia veterinary association. Pp: 15.

[33] Solomon, G., \& Kaaya, G. (1996). Studies on the developmental and survival of Rhipicephaluspulchelu and Amblyoma gemma under field condition. Ethiopia Vet.Assoc.

[34] Solomon, G., Kaaya, G., Feseha, G, \& Getachew, T. (1998). Ticks and tick borne parasites associated with indigenous cattle in Dituyura ranch, southern Ethiopia insect science and its application.

[35] Solomon, G., \& Kassa, G. (2001). Development reproductive capacity and survival of Amblyomma variegartum and Boophilus decoloratus in relation host resistance and climatic factors under different field conditions. Vet. Prasitol., 75: Pp.241-253.

[36] Solomon, G., Night, M., \& Kaaya, GP. (2001). Seasonal variation of ticks on calves at Sabetha, Western Shewa zone. Ethiopia Vet. J. 7(1\&2): Pp.17-30.

[37] Stata Corporation. (2005). Stata Statistical Software .Release 9.0. College Station, Texas.

[38] Tesfanesh, G. (1993). Tick and tick borne diseases of cattle in North Omo administrative Zone, DVM thesis, Faculty of veterinary medicine, Addis Ababa University, Debrezeit, Ethiopia, Pp: 150.

[39] Thrusfield, M. (2005). Veterinary epidemiology, 3rd edition. Blackwell science.Ltd. Oxford. Pp. 232-234.

[40] Walker, R., A. Butiur, S., Estrada-pen, A., Hora G., Latif, A., Pergam \& Preston, P. (2003). Tick of domestic animal in Africa, Guide to Identification Tick Species, Pp: 3-210.

[41] Yitbarek, G. (2004). Tick species infesting livestock in Jimma, Southern Western Ethiopia, DVM Thesis, Faculty of Veterinary Medicine, Addis Ababa University, DebreZeite, Ethiopia.

*Corresponding author.

E-mail address: clexhena@gmail.com 